1975, the then President of the Union, Professor Dorothy Hodgkin, suggested that a fund might be set up, in memory of past Presidents, for use in emergencies and under special or difficult circumstances, to help crystallographers to take part in the activities of the Union. The fund would be operated by the President and by the General Secretary and Treasurer. Professor Hodgkin's suggestion was well received.

Professor Hodgkin has been given the Fankuchen Award for 1977 of the American Crystallographic Association and has donated part of this award to initiate the President's Fund. Members of the crystallographic community are invited to send donations to the fund to the Executive Secretary, International Union of Crystallography, 13 White Friars, Chester $\mathrm{CH} 1$ 1NZ, England.

\section{International Tables for X-ray Crystallography}

Volume I (Symmetry Tables) of International Tables for X-ray Crystallography has been reprinted and is now available. The Executive Committee had previously decided not to reprint it because the first volume of the new series, on direct space, was expected to be published early in 1977. However, its publication has been delayed and it was felt that a reprint of the present Volume I would be necessary in the meantime.

Because of increases in printing costs it has been necessary to raise the price of Volume I to $£ 15.00$ and, because of the steady drop in the value of sterling with respect to other currencies, it has also been necessary to revise the sterling prices of the other volumes. Volume II (Mathematical Tables) and Volume III (Physical and Chemical Tables) now cost $£ 11.50$ each, whilst Volume IV (Revised and Supplementary Tables for Volumes II and III) costs $£ 14.00$. Copies may be obtained at the special reduced prices of $£ 10.00$ for Volume I, $£ 6.00$ for Volumes II or III and $£ 9.00$ for Volume IV by bona fide crystallographers, who must give an undertaking when purchasing that the volume is for their personal use only. Orders may be placed direct with the publishers, The Kynoch Press, Witton, Birmingham B6 7BA, England, or with Polycrystal Book Service, PO Box 11567, Pittsburgh, Pa 15238, USA, from whom prospectuses may also be obtained.

\section{Notes and News}

Announcements and other items of crystallographic interest will be published under this heading at the
discretion of the Editorial Board. The notes (in duplicate) discretion of the Editorial Board. The notes (in duplicate)
should be sent to the Executive Secretary of the Internashould be sent to the Executive Secretary of the InternaUnion of Crystallography, 13 White Friars, Chester $\mathrm{CH} 1$ 1NZ, England).

\section{Co-operation Schemes for Crystallographers in Develop- ing Countries}

The attention of crystallographers in developing countries, and also other crystallographers interested in helping their colleagues in these countries, is drawn to the announcement of the introduction of special co-operation schemes which was published recently in the Notes \& News Section of the Union's journals [Acta Cryst. (1977), A 33, 251; B 33, 317; J. Appl. Cryst. (1977), 10, 76] under the heading European Crystallographic Committee. Professor Feil and Dr Kennard would be grateful to anyone who is able to bring these schemes to the attention of the crystallographers for whom they are intended or can give them further publicity in any way.

\section{Documentation on Crystal Growth}

Professor A. M. Vergnoux has compiled and published a book entitled Documentation sur les Synthèses Cristallines, listing laboratories in Belgium, France, Italy and Spain which produce single crystals. This work is an extension of a previous brochure compiled by Professor Vergnoux in 1973. Copies may be obtained by sending six international reply coupons (to cover postage costs) to Professor A. M. Vergnoux, 42 rue Ste Claire, 87000 Limoges, France.

Dr R. Nitsche and Dr A. Räuber have complied a book entitled Information über Kristallzüchtung, on behalf of the German Association for Crystal Growth. The book lists laboratories in the Federal Republic of Germany, Switzerland and The Netherlands that are engaged in crystal growth, and it collects data on materials that have been grown during recent years in these laboratories. Copies may be obtained from $\mathrm{Dr} A$. Räuber. Institut für Angewandte Festkörperphysik, Eckerstr. 4, D-7800 Freiburg, Federal Republic of Germany, at a price of DM 15 plus an additional DM 2 for postage.

\section{Book Reviews}

Works intended for notice in this column should be sen direct to the Book-Review Editor (J. H. Robertson, School of Chemistry, University of Leeds, Leeds LS2 9JT. England). As far as practicable books will be reviewed in a country different from that of publication.

\section{Characterisation of epitaxial} semiconductor films. Edited by H. Kressel. Pp. xii +216. Elsevier, 1976. Price Dfl 77.00, US $\$ 29.75$.

The silicon chip was, and still is, the basis of most integrated circuits, but much effort has been spent in recent years on developing thin film, large area semiconductors by epitaxic growth. Such films may replace the chips, at least in some applications. The book is a compilation of review papers written by workers in this field. It consists of four chapters treating methods of making various types of film, and six with descriptions of methods for examining thin films in general and semiconductor films in particular.

Type III-V semiconductors such as GaAs, GaP, and GaN may be deposited on single crystals of sapphire or spinel using organometallic vapour. How the resulting film depends on growth parameters is described in the first chapter. The third and fourth chapters deal with deposits of $\mathrm{SiC}$ from $\mathrm{SiCl}_{4}$ and $\mathrm{C}_{6} \mathrm{H}_{14}$ on $\mathrm{Si}$, and with Si sublimated onto sapphire or diamond respectively. The subject of the second chapter, the effect of hydrogen on PbSe films, appears somewhat out of the context.

Two of the remaining six chapters deal with the electrical characterization of the films, one from a practical point of view, while the other deals with specimen and electrode geometry. One chapter contains a good survey of the numerous methods of surface examination at present available to the physicist, in which the stimulus may be UV photons, X-rays, electrons or ions, and the detected signal may belong to any one of these categories. Chemical and electrochemical polishing of $\mathrm{GaAs}$ as means of polishing or decorating the surface are described in detail in another chapter. Of the remaining two chapters, one analyses crystallographic defects in Si films, tracing them back to various causes, whilst the other gives a highly readable account of the use of the Lang camera both for transmission and reflexion.

The book may be of limited concern to those interested in epitaxy for its own sake because of its restriction to semiconductors. The chapters describing methods of examination are valuable, and 